\title{
The gut bacteria of an invasive amphibian respond to the dual challenges of range-expansion and parasite attack
}

2 Jia Zhou ${ }^{1,6^{*},}$ Tiffanie Maree Nelson², Carlos Rodriguez Lopez $^{3}$, Shao Jia Zhou ${ }^{1,4}$, Georgia

3 Ward-Fear ${ }^{5}$, Katarina C. Stuart ${ }^{6}$, Richard Shine ${ }^{5}$, Lee Ann Rollins ${ }^{6}$

4

$5{ }^{1}$ School of Agriculture, Food and Wine, University of Adelaide, Waite Campus, PMB 1 Glen

6 Osmond, South Australia, Australia, 5064.

$7 \quad{ }^{2}$ Queensland Facility for Advanced Bioinformatics, School of Medicine, Menzies Health Institute

8 Queensland, Building G40, Level 9, Gold Coast Campus, Griffith University, Southport, QLD,

9 Australia, 4215.

$10{ }^{3}$ Environmental Epigenetics and Genetics Group, Department of Horticulture, College of Agriculture,

11 Food and Environment, University of Kentucky, Lexington, KY, USA, 40546.

$12{ }^{4}$ Robinson Research Institute, University of Adelaide, South Australia, Australia, 5005

$13{ }^{5}$ Department of Biological Sciences, Macquarie University, North Ryde, NSW, Australia, 2109.

$14{ }^{6}$ Ecology \& Evolution Research Centre, School of Biological, Earth and Environmental Sciences,

15 University of New South Wales, Biological Sciences South (E26) UNSW, Kensington, Australia, 162052

$19 *$ Correspondence:

20 Jia Zhou

21 E-mail: jiazhou0116@gmail.com

22 Keywords: microbiome, Cane toad, 16S rRNA, host-parasite 
Word count: 6334 .

\section{Abstract}

26 Gut bacterial communities influence, and are influenced by, the behaviour and ecology of their hosts.

27 Those interactions have been studied primarily in humans and model organisms, but we need field research to understand the relationship between an organism's gut bacteria and its ecological challenges, such as those imposed by rapid range expansion (as in invasive species) and the presence of host-manipulating parasites. Cane toads (Rhinella marina) provide an excellent model system in this respect, because the species' ongoing colonization of Australia has enforced major changes in phenotypic traits (including behaviour), and lungworm parasites (Rhabdias pseudosphaerocephala)

modify host gut function in ways that enhance the viability of lungworm larvae. We collected female toads from across the species' invasive range and studied their morphology, behaviour, parasite infection status and gut bacterial community. Range-core versus range-edge toads differed in morphology, behaviour, gut bacterial composition and predicted gut bacterial function but did not differ in the occurrence of parasite infection nor in the intensity of infection. Toads infected with lungworms differed from uninfected conspecifics in gut bacterial composition and diversity. Our study demonstrates strong associations between gut bacterial community and host ecology and behaviour.

\section{Introduction}

The bacterial community within an organism's intestines can be strongly influenced by host behaviour and ecology, such as habitat selection and diet [1-5]. But that interaction runs both ways because gut bacteria can influence behaviour and ecology of the host. For example, transferring gut contents can modify the recipient host's behaviour (exploratory behaviour, Mus musculus [6]; emotional reactivity, Coturnix japonica [7]). Similarly, altering gut microbial communities by administering antibiotics or altering dietary composition triggered aggressive behaviour in leafcutting ants (Acromyrmex echinatior [8]). Remarkably, changes in only a single bacterial species within the gut can affect behaviour of the host (e.g., Drosophila melanogaster [9]; Danio rerio [10];

51 M. musculus [11]). Gut microbiota can also affect mating choices [12] and foraging [13-15]. 
52 To date, most evidence for effects of intestinal bacteria on host behaviour comes from studies on

53 humans and "model organisms". To elucidate the functional significance of this phenomenon, we

54 need to extend such studies to free-ranging animals, incorporating a wider range of taxa [16].

55 Invasive species offer good models for such research, because novel challenges in the invaded range

56 create an opportunity to compare closely-related organisms exposed to profoundly different

57 environments $[17,18]$. Host-parasite relationships also may be disrupted during biological invasions,

58 due to processes such as "enemy release" (loss of co-evolved native pathogens from the native range

59 [19]). Parasites can manipulate host behaviour and physiology in ways that enhance parasite fitness

60 but reduce host fitness [20]. Thus, if the gut bacterial community provides a mechanism for such

61 effects, parasite-infected individuals should exhibit different gut bacteria than uninfected

62 conspecifics.

63 These ideas suggest two predictions: (i) that the gut bacterial community should differ between

64 populations of an invasive species (e.g., between the range-core and the invasion-front); and (ii) that

65 the gut bacterial community should differ between parasitized hosts and non-parasitized conspecifics.

66 The colonization of Australia by cane toads (Rhinella marina) provides a robust opportunity to test

67 these predictions. Since their release in north-eastern Australia in 1935, toads have dispersed into

68 areas that are much hotter and more seasonally arid than in the native range or the initial release sites

69 [21]; and toads have brought with them a native-range nematode lungworm (Rhabdias

70 pseudosphaerocephala) that can have devastating impacts on host viability, and induces behavioural

71 and physiological changes in the host [22]. Notably, infected toads produce copious watery faeces

72 [22]; hence, we expect lungworm-infected toads to exhibit different gut bacterial communities than

73 uninfected individuals.

75 Methodology

\section{Study species, sample collection and behavioural assays}

77 Cane toads are native to South America, and were introduced into Australia in 1935 as a biocontrol for pests of sugar cane crops [23]. As the toads spread through tropical Australia, they fatally poisoned many native predators [23]. Toads from range-core populations (eastern Australia) differ

80 from invasion-front conspecifics (in north-western Australia) in phenotypic traits that confer 81 increased dispersal ability, such as endurance [24], limb morphology [25], boldness and exploratory

82 behaviour $[17,26]$. Toads from the invasion-front also have lower rates of infection of the co- 
83 introduced parasitic lungworm [27]. Drivers of variation in invasion-related behaviours in this

84 species include genetics, morphology, habitat, diet, prior experience and parasites [17,28-31].

85 However, the possible role of gut bacteria as a potential driver of behavioural shifts across the invasive range has not been studied.

We hand-captured 60 adult females from three sites on the invasion-front and three sites in the rangecore (Table S1). We conducted brief behavioural assays upon collection including: (i) struggle score (number of kicks after being captured until toad remains still for 5 seconds) and struggle likelihood; and (ii) righting effort (time to right itself, number of kicks within two minutes after toad is placed on its dorsal side, and righting effort likelihood [17]. These measures are predictive of traits including speed and stamina (K. Stuart, pers. comm.), suggesting that these simple assays may reveal a toad's dispersal potential. We then placed animals into individual, moist, calico bags and weighed, measured (snout urostyle length; SUL) and euthanised them by injecting tricaine methanesulfonate (MS222) buffered with bicarbonate of soda.

We dissected the toads and scored the presence of two types of toad parasite: the gut-encysted physalopterine larvae [32] and adult lungworms [22,33]. Lungworm larvae pass through the gut, but are less easily detected and reliably counted than are adult lungworms. From each toad, we removed $0.3 \mathrm{~cm}$ of colon near the cloaca (including gut contents) and preserved it in $95 \%$ ethanol (see Supplementary Material for justification of sampling protocols).

\section{Analyses}

103 We compared host morphology and behaviour between regions (range-core versus invasion-front), and as a function of infection status (lungworm infected versus non-infected). Because body length (SUL) and mass were correlated, we only included SUL as our measure of host morphology in

106 further analyses. We used a t-test to compare mean SUL between regions and infected/non-infected 107 toads. For associations between region or infection status with host characteristics or behavioural

108 traits, we used SUL as a covariate in generalized linear models (GLM). See Supplementary Material

109 for details of statistical analyses. 
111 Laboratory methods and data pre-processing for characterizing gut bacterial community composition and predicted functions are described in Supplementary Material. Briefly, we calculated within-

113 individual (alpha) bacterial diversity and between-site (beta) bacterial diversity. For the latter

114 variable, we subset our data to include the Core50 gut community (Amplified Sequence Variants

115 (ASVs) present in a minimum of 50\% of toads from each site [2]). We predicted bacterial functions

116 and generated pathway abundance based on Core50 ASVs. We compared bacterial composition and

117 predicted function between regions, and between lungworm-infected and non-infected toads. We

118 identified differences in individual ASVs and predicted bacterial functions between range-core and

119 invasion-front toads and identified associations between host characteristics (including infection with 120 parasites) with bacterial communities and predicted bacterial functions. Analyses were conducted in 121 QIIME2 [34], PICRUST2 [35], and R packages in R version 4.0.2 [36].

\section{Results}

\section{Ecological traits}

124 Wild-caught invasion-front toads were larger than range-core toads (Tables S2, S3; mean SUL t = $1252.54, \mathrm{df}=53.90, \mathrm{p}=0.014)$. Neither counts nor presence of parasites (lungworm and gut) differed 126 significantly across the range (Table S2). Range-core toads were more likely to struggle (Tables S2, $127 \mathrm{~S} 3 ; \mathrm{p}=0.008,95 \% \mathrm{CI}$ : core [-0.174, 0.005], edge [-0.023, 0.199]) and, in those that did struggle, the 128 number of struggle movements was higher for range-core toads (Tables S2, S3; p = 0.002, 95\% CI: 129 core [-0.057, 0.026], edge [0.046, 0.2]). Range-core toads also were more likely to attempt to right 130 themselves ( $\mathrm{p}=0.036,95 \%$ CI: core [-0.092, 0.04], edge [-0.006, 0.19]), but righting effort and 131 righting time did not differ significantly between geographic regions (Tables S2, S3).

133 Because there were no significant differences in prevalence or intensity of lungworm between the 134 range-core and invasion-front toads (Table S2), we combined samples to analyse correlates of 135 lungworm infection. Infected toads were similar in SUL to non-infected toads (Tables S3, 4; $\mathrm{t}=0.86$, $136 \mathrm{df}=57.19, \mathrm{p}=0.393$ ), with no significant behavioural differences between the two groups (Table S3, $1374)$.

\section{Gut bacterial community composition and predicted bacterial function}

140 Alpha diversity did not differ significantly between regions (Supplementary Material), but beta 141 diversity of bacterial taxonomic communities differed between regions (Figures $1 \mathrm{~A}, \mathrm{~S} 1 ; \mathrm{R}^{2}=0.050$, 
$142 \mathrm{~F}=3.050, \mathrm{p}<0.001$ ) and sampling sites (Table S5; all p-values < 0.001). Among 230 ASVs that

143 were assigned to family level, the abundance of 124 ASVs differed between the colons of range-core

144 versus invasion-front toads (Table S6). The number of significantly different ASVs in each phylum

145 were: Bacteroidetes (60 ASVs), Firmicutes (55 ASVs), Proteobacteria (7 ASVs), Actinobacteria (1

146 ASVs), Verrucomicrobia (1 ASV) (Table S6, Figure 2A).

148 Among the identified 474 predicted bacterial functions, we found significant differences between

149 invasion-front and range-core toads (Figure $1 \mathrm{~B} ; \mathrm{R}^{2}=0.064, \mathrm{~F}=4.110$, p-value $=0.002$ ). Pairwise

150 tests between sampling sites indicated that Kununurra toads had different bacterial functions to

151 Rossville $(\mathrm{p}$-value $=0.009)$ and Lucinda toads $(\mathrm{p}$-value $=0.046)$, but no other sites differed

152 functionally from each other (Table S7; all other p-values > 0.05). In total, 84 predicted bacterial

153 functions differed between invasion-front and range-core toads (Table S8, Figure 2B). Range-core

154 toads had more abundant bacterial function in the superpathway of pyrimidine ribonucleosides

155 degradation $(\log 2$ FoldChange $=5.98)$ and less abundant bacterial function in phosphopantothenate

156 biosynthesis III (log2FoldChange $=-4.98)$, superpathway of sialic acids and CMP-sialic acids

157 biosynthesis $(\log 2$ FoldChange $=-4.89)$ and factor 420 biosynthesis $(\log 2$ FoldChange $=-4.72)$ than

158 did invasion-front toads (Table S8, Figure 2B). Among the 30 most abundant functions, range-core

159 toads had lower bacterial function in urate biosynthesis/inosine 5'-phosphate degradation

160 (log2FoldChange $=-0.10)$ than did invasion-front toads (Figure 3, Table S8).

161

\section{Associations between ecological traits and intestinal bacteria}

163 To assess correlates of gut bacterial composition and function, we compared characteristics of

164 individual hosts to bacterial variation. Only the occurrence of lungworms was significantly

165 associated with the bacterial composition $\left(\mathrm{R}^{2}=0.128, \mathrm{p}=0.02\right)$ (Table 1; Figure $\left.\mathrm{S} 2 \mathrm{~A}, \mathrm{~B}\right)$.

167 In a redundancy analysis combining ecological traits measured here, the model that explained the

168 most variation in the bacterial community assemblage included only the occurrence of lungworms

$169 \quad(\mathrm{AIC}=178.58)$. The best model to explain variation in predicted bacterial functions included the

170 likelihood of righting $(\mathrm{AIC}=53.613)$, the occurrence of lungworms $(\mathrm{AIC}=54.297)$ and righting

171 time $(\mathrm{AIC}=56.912)$. The combination of these three factors explained $17.8 \%$ of total variation in

172 predicted bacterial functions (Figure 4). 
174 In explicit tests of whether bacterial community assemblages differed in infected versus non-infected

175 toads, we found a significant association with lungworm occurrence (Table 2, p=0.005). Intensity of

176 lungworm infection was not significantly associated with gut bacterial community but did have a

177 significant interaction with region in this analysis (Table $2, \mathrm{p}=0.04$ ).

\section{Discussion}

179 Bacteria influence animal behaviour in diverse ways [16,37], but the ecological drivers of variation in

180 gut bacterial composition remain largely unstudied. Our analyses of cane toads from two regions

181 within their invasive range documents substantial variation in community assemblage and function of

182 gut bacteria. Importantly, that variation was associated with two traits that we predicted to influence

183 gut bacterial assemblages: invasion history and parasite infection. Interestingly, toad behaviour

184 differed across the invasive range, and toad righting behaviour was associated with bacterial function

185 but not with parasite infection.

\section{Geographic divergence in gut bacteria}

188 First, we consider the differences in gut bacteria between toads from the invasion-front and the 189 range-core. Although these populations have been separated by less than a century, the toads have 190 diverged remarkably in morphology, physiology and behaviour and much of that divergence is 191 heritable $[38,39]$. Some of those shifts likely reflect evolutionary pressures for increased rates of

192 dispersal, due to adaptive (natural selection) and non-adaptive (spatial sorting) mechanisms [40,41].

193 Other geographically variable aspects of toad phenotypes likely are responses to different climatic conditions in the newly-invaded regions (hot, seasonally arid) compared to the range-core (cooler, more equable climate) [42]. Similar geographic divergence has been reported for the microbiome on the toad's skin [43]. Our data illustrate that the invasion of Australia by cane toads has been accompanied by substantial divergence in gut bacterial communities. Alpha diversity in gut bacteria was similar in invasion-front and range-core individuals, but there were differences in both the gut bacteria composition and predicted bacterial function between toad populations across the species' Australian invasive range. Predicted bacterial functions better explained cane toad righting behaviour than did gut bacterial community composition. Intriguingly, similarity between gut bacterial communities between individuals within regions in Australia is related to the similarity of their host's epigenome, and this relationship is strengthened in populations where genetic diversity is lowest, 
are complex, and that a clear understanding of these relationships requires careful consideration of numerous environmental, host and gut bacterial factors.

208 The diversity and composition of bacterial communities differed between range-core and invasion-

209 front toads, despite an overall similarity in their dominant phyla and alpha diversity. ASVs in the

210 family Veillonellaceae were higher at the invasion-front (Figure 2A). The abundance of this bacterial

211 family may influence host metabolic regulation. For example, in Brandt's voles (Lasiopodomys

212 brandtii) exposed to colder temperatures, voles which huddled had more Veillonellaceae and more

213 short-chain fatty acids (SCFAs) in their intestines than did non-huddling voles [45]. This family

214 produces SCFAs such as propionic acid [46,47], which can increase locomotor activity [48]. The link

215 to host metabolic regulation suggests that invasion-front toads might fuel their invasion in this way

216 [24]. ASVs from another family of SCFA-producing bacteria, Clostridiaceae [49], were also higher

217 in invasion-front toads than those from the range-core. Furthermore, the family Veillonellaceae may

218 be associated with host sociality. A reduction of Veillonellaceae has been observed in children with

219 Autism Spectrum Disorder, often known for desiring social isolation [50]. Higher abundance of

220 Veillonellaceae in invasion-front toads could foster their "bolder" personality, retaining a higher

221 propensity for exploration and risk-taking [26,51].

222 Several other ASVs that differed across the toad's range also may affect behaviour. ASVs from the

223 family Peptococcaceae, more common in invasion-front toads (Figure 2A), are related to host

224 neurotransmitter levels (noradrenaline linking visual awareness to external world events [52]). For

225 example, Peptococcaceae levels in the caecum are positively correlated with noradrenaline levels in

226 mice [53]. ASVs from family Bacillaceae, lower in invasion-front toads (Figure 2A), might be

227 related to host anxiety (e.g., abundant in methamphetamine-treated rats [54], and in exercised versus

228 sedentary mice [55]). Abundant Bacillaceae might induce anxiety-like behaviours, thus intensifying

229 the stress response [54] and decreasing exploratory behaviour in new environments [56]. In

230 summary, invasion-front toads possessed gut bacterial communities that in other studies have been

231 associated with SCFAs production and neurotransmitters. That pattern supports the idea that gut

232 microbes in invasion-front toads may increase locomotor ability, alertness and propensity for

233 exploration and risk-taking. In comparison, range-core toads possessed bacterial taxa that have been

234 associated with anxiety, and a decreased propensity to explore. 
235 Geographic variation was less obvious in the predicted bacterial functional groups than in community

236 composition (Figure 1), consistent with the hypothesis that bacterial function is more conservative

237 than taxonomic composition (e.g. in fire salamanders [2]). Different gut microbiota can have similar

238 bacterial functions, increasing resilience and functional stability [2,3,57]. Despite this broad

239 similarity, bacterial functions differed between range-core and invasion-front toads. These

240 differences included those involved in functional pathways related to food sources and metabolism.

241 Invasion-front toads had less bacterial function in the superpathway of pyrimidine ribonucleosides

242 degradation, which provides a nitrogen source for microbes [58] and plays an important role in

243 perturbations in the uridine monophosphate (UMP) biosynthetic pathways. This pathway allows the

244 bacterial cell to sense signals such as starvation, nucleic acid degradation, and availability of

245 exogenous pyrimidines, and to adapt the production of the extracellular matrix to changing

246 environmental conditions [59]. This function might help to explain the disappearance of

247 Verrucomicrobia as a dominant taxon. As for microbe metabolism, invasion-front toads have higher

248 abundance of bacterial functions in factor 420 biosynthesis, critical to bacterial metabolism and

249 mediating important redox transformations involved in bacterial persistence, antibiotic biosynthesis,

250 pro-drug activation, and methanogenesis [60].

We also detected geographic variation in bacterial functional pathways that contribute to host health.

252 Invasion-front toads exhibited bacterial functions beneficial to host health and immunity: (i)

253 phosphopantothenate biosynthesis (involved in bacterial production of coenzyme A [61]); and (ii)

254 superpathway of sialic acids biosynthesis (involved in immunity including acting as host receptors

255 and pathogen decoys for viruses and bacteria [62] and especially critical for preventing neural tissue

256 damage [63]). Despite this abundance of health-promoting bacterial functions, these toads may also

257 face health challenges. Invasion-front toad bacteria had a higher abundance of urate biosynthesis

258 function (urate biosynthesis/inosine 5'-phosphate degradation, the only significantly different one out

259 of the top 30 abundant functions), which affects serum urate levels [64]. High levels of urate can

260 result in the formation of needle-like crystals of urate in the joints (gout), perhaps related to severe

261 spinal arthritis in invasion-front cane toads [65].

\section{Associations between lungworms and host gut bacteria}

264 Pathogens and parasites impact the composition of the host microbiota and can modify host

265 behaviour in a manner that improves parasite transmission and survival [66-68]. Lungworms can

266 affect cane toad locomotor performance and reduce host endurance, curtailing oxygen supply from 
infected lungs [69]. Lungworms also can alter a cane toad's thermal preference and manipulate the timing and location of defecation, thereby enhancing lungworm egg production and larval survival [22]. Lungworms are reported to lag behind their host on the invasion-front by 2-3 years [27] and to affect righting behaviour (prolongs righting time [70]). In the current study, although we collected invasion-front toads in recently invaded areas, we found no difference in lungworm presence or intensity between the invasion-front versus range-core toads, nor did we find behavioural differences in lungworm-infected versus uninfected toads.

Infection by parasitic lungworms was associated with differences in gut bacteria. Here, the direction of causation is less ambiguous than is the case for geographic variation in the gut bacteria. It seems unlikely that a toad's bacteria affect its probability of carrying adult lungworms, although bacterialdriven differences in habitat selection might create such a link. Instead, we suggest that the presence of lungworms induces a shift in gut bacteria. Consistent with that hypothesis, experimental trials have shown that lungworms modify gastric function in their hosts, changing the volume and consistency of faeces produced in ways that enhance survival of larval lungworms [22]. Shifts in the microbiome inside the gut might be either causes or consequences of that shift in gastric function. Moreover, $C$. elegans are known to prefer specific bacterial foods [71], suggesting that lungworm larvae may also feed selectively on bacteria in the gut, generating differences in bacterial communities between lungworm-infected toads versus non-infected conspecifics. Additionally, gut bacteria may affect lungworms via microbiome-induced shifts in host immunity [72].

\section{Associations between host behaviours and gut bacteria}

Interestingly, behaviours including righting effort likelihood and righting time were associated more closely with predicted gut bacterial functions than with bacterial taxonomic composition. Multiple identified taxa may share the same bacterial function, or one taxon may contribute to multiple bacterial functions, obscuring the relationship between host behaviour and bacterial taxonomic

293 composition. Nonetheless, these relationships we found between gut bacterial function and righting behaviours may be related to toad health and/or rearing conditions. A dampened stress response (lower corticosterone levels) in invasion-front toads [73] could result from higher abundance of bacterial functions beneficial to host health and immunity, especially the superpathway of sialic acids biosynthesis [63]. Further, invasion-front toads are more reluctant to flee in simulated predation trials 
studies are needed to clarify causal relationships between stress responses, proactive behaviours, and gut bacterial functions, our results indicate that host behaviour and gut bacterial functions are related, suggesting that gut bacteria may be an important driver of invasion.

Our study has identified patterns rather than testing alternative hypotheses about underlying causal processes. To clarify causal mechanisms underlying the geographic divergence in gut bacteria across the toads' Australian range, future studies could use reciprocal transplantation to examine if (and how) their gut bacteria respond to novel environmental conditions. Breeding these animals, and raising their offspring under common-garden conditions, could reveal the degree to which a toad's gut bacteria is driven by host genetics versus their rearing conditions [75,76]. To clarify the hypothesis that changes in gut bacteria mediate the ability of lungworm parasites to modify host gut function, we could implant colon contents from infected into uninfected toads. In short, our discovery of strong associations between gut bacteria and important facets of toad ecology provides the opportunity to move to hypothesis-testing experimental studies.

315 Our research illustrates that during invasion, as a species expands across a novel and variable

316 landscape, a complex relationship between host behaviour, its parasite community, and its

317 microbiome may unfold. A clearer understanding of these relationships and how they influence the

318 rate of expansion are key to understanding the role of the holobiont during invasion [77]. Such

319 studies also will advance our understanding of co-evolution and may facilitate innovative approaches

320 to invasive species management.

Ethics

323 Approved by University of Adelaide Animal Ethics Committee (S-2018-056).

\section{Author Contributions}

326 Designed research: JZ, TMN, CRL, SJZ, LAR; performed research: JZ, CRL, GWF, KS, LAR; 327 analyzed data: JZ, TMN, CRL, SJZ, KS, LAR; drafted manuscript: JZ, RS, TMN, CRL, SJZ, GWF, 328 KS, LAR.

\section{Funding}


330 This project was supported by the Holsworth Wildlife Research Endowment and University of

331 Adelaide Graduate Research Scholarship to JZ, and a UNSW Scientia Fellowship to LAR. CMRL is

332 partially supported by the National Institute of Food and Agriculture (AFRI Competitive Grant

3331018617 and Hatch Program 1020852).

\section{Acknowledgments}

335 We thank Dr. Alice Russo and Ms. Rita Kurpiewski for field assistance, and Dr. Eve Slavich (UNSW

336 Stats Central) for statistical advice.

\section{Data Availability Statement}

338 Supplementary methods and results available online. Code available at:

339 https://github.com/jiazhou0116/gut-microbiome-analyses-2. Sequence data are available in NCBI

340 Sequence Read Archive (PRJNA670039). Raw ecological data available on Dryad

341 (doi:10.5061/dryad.v15dv41tw). 
[1] Hopkins WA. Amphibians as models for studying environmental change. ILAR J 2007;48:270-7. doi:10.1093/ilar.48.3.270.

[2] Bletz MC, Goedbloed DJ, Sanchez E, Reinhardt T, Tebbe CC, Bhuju S, et al. Amphibian gut microbiota shifts differentially in community structure but converges on habitat-specific predicted functions. Nat Commun 2016;7:13699. doi:10.1038/ncomms13699. specialists of the gut microbiota of frogs reflect habitat differences and agricultural activity. Front Microbiol 2017;8:2670. doi:10.3389/fmicb.2017.02670.

[4] Scott KP, Gratz SW, Sheridan PO, Flint HJ, Duncan SH. The influence of diet on the gut microbiota. Pharmacol Res 2013;69:52-60. doi:10.1016/j.phrs.2012.10.020.

[5] Zmora N, Suez J, Elinav E. You are what you eat: diet, health and the gut microbiota. Nat Rev Gastroenterol Hepatol 2019;16:35-56. doi:10.1038/s41575-018-0061-2.

[6] Bercik P, Denou E, Collins J, Jackson W, Lu J, Jury J, et al. The intestinal microbiota affect central levels of brain-derived neurotropic factor and behavior in mice. Gastroenterology 2011;141:599-609, 609.e1. doi:10.1053/j.gastro.2011.04.052.

[7] Kraimi N, Calandreau L, Zemb O, Germain K, Dupont C, Velge P, et al. Effects of gut microbiota transfer on emotional reactivity in Japanese quails (Coturnix japonica). J Exp Biol 2019;222. doi:10.1242/jeb.202879.

[8] Teseo S, van Zweden JS, Pontieri L, Kooij PW, Sørensen SJ, Wenseleers T, et al. The scent of symbiosis: gut bacteria may affect social interactions in leaf-cutting ants. Anim Behav 2019;150:239-54. doi:10.1016/j.anbehav.2018.12.017.

[9] Schretter CE, Vielmetter J, Bartos I, Marka Z, Marka S, Argade S, et al. A gut microbial factor modulates locomotor behaviour in Drosophila. Nature 2018;563:402-6. doi:10.1038/s41586018-0634-9.

[10] Borrelli L, Aceto S, Agnisola C, De Paolo S, Dipineto L, Stilling RM, et al. Probiotic modulation of the microbiota-gut-brain axis and behaviour in zebrafish. Sci Rep 2016;6:30046. doi:10.1038/srep30046.

[11] Savignac HM, Kiely B, Dinan TG, Cryan JF. Bifidobacteria exert strain-specific effects on stress-related behavior and physiology in BALB/c mice. Neurogastroenterol Motil 2014;26:1615-27. doi:10.1111/nmo.12427.

[12] Sharon G, Segal D, Ringo JM, Hefetz A, Zilber-Rosenberg I, Rosenberg E. Commensal bacteria play a role in mating preference of Drosophila melanogaster. Proc Natl Acad Sci USA 2010;107:20051-6. doi:10.1073/pnas.1009906107.

[13] Vogel H, Shukla SP, Engl T, Weiss B, Fischer R, Steiger S, et al. The digestive and defensive 
basis of carcass utilization by the burying beetle and its microbiota. Nat Commun 2017;8:15186. doi:10.1038/ncomms15186.

[14] Wong AC-N, Wang Q-P, Morimoto J, Senior AM, Lihoreau M, Neely GG, et al. Gut Microbiota Modifies Olfactory-Guided Microbial Preferences and Foraging Decisions in Drosophila. Curr Biol 2017;27:2397-2404.e4. doi:10.1016/j.cub.2017.07.022.

[15] Jones JC, Fruciano C, Marchant J, Hildebrand F, Forslund S, Bork P, et al. The gut microbiome is associated with behavioural task in honey bees. Insectes Soc 2018;65:419-29. doi:10.1007/s00040-018-0624-9.

[16] Davidson GL, Raulo A, Knowles SCL. Identifying Microbiome-Mediated Behaviour in Wild Vertebrates. Trends Ecol Evol (Amst) 2020. doi:10.1016/j.tree.2020.06.014.

[17] Stuart KC, Shine R, Brown GP. Proximate mechanisms underlying the rapid modification of phenotypic traits in cane toads ( Rhinella marina) across their invasive range within Australia. Biological Journal of the Linnean Society 2019;126:68-79. doi:10.1093/biolinnean/bly150.

[18] Wagener C, Mohanty NP, Measey J. The gut microbiome facilitates ecological adaptation in an invasive vertebrate. BioRxiv 2020. doi:10.1101/2020.12.10.418954.

[19] Colautti RI, Ricciardi A, Grigorovich IA, MacIsaac HJ. Is invasion success explained by the enemy release hypothesis? Ecol Lett 2004;7:721-33. doi:10.1111/j.1461-0248.2004.00616.x.

[20] Poulin R. Parasite manipulation of host behavior: an updateand frequently asked questions. Advances In The Study Of Behavior, vol. 41, Elsevier; 2010, p. 151-86. doi:10.1016/S00653454(10)41005-0.

[21] Tingley R, Ward-Fear G, Schwarzkopf L, Greenlees MJ, Phillips BL, Brown G, et al. New weapons in the toad toolkit: A review of methods to control and mitigate the biodiversity impacts of invasive cane toads (rhinella marina ). Q Rev Biol 2017;92:123-49. doi:10.1086/692167.

[22] Finnerty PB, Shine R, Brown GP. Survival of the feces: Does a nematode lungworm adaptively manipulate the behavior of its cane toad host? Ecol Evol 2018;8:4606-18. doi:10.1002/ece3.3870.

[23] Shine R. The ecological impact of invasive cane toads (Bufo marinus) in Australia. Q Rev Biol 2010;85:253-91. doi:10.1086/655116.

[24] Llewelyn J, Phillips BL, Alford RA, Schwarzkopf L, Shine R. Locomotor performance in an invasive species: cane toads from the invasion front have greater endurance, but not speed, compared to conspecifics from a long-colonised area. Oecologia 2010;162:343-8. doi:10.1007/s00442-009-1471-1.

415 [26] Gruber J, Brown G, Whiting MJ, Shine R. Geographic divergence in dispersal-related 
427

428

429

430

431

432

433

434

435

436

437

438

439

440

441

442

443

444

445

446

447

448

449

450

451

452

behaviour in cane toads from range-front versus range-core populations in Australia. Behavioral Ecology And 2017.

[27] Phillips BL, Kelehear C, Pizzatto L, Brown GP, Barton D, Shine R. Parasites and pathogens lag behind their host during periods of host range advance. Ecology 2010;91:872-81. doi:10.1890/09-0530.1.

[28] Child T, Phillips BL, Shine R. Abiotic and biotic influences on the dispersal behavior of metamorph cane toads (Bufo marinus) in tropical Australia. J Exp Zool A Ecol Genet Physiol 2008;309:215-24. doi:10.1002/jez.450.

[29] Selechnik D, Richardson MF, Shine R, DeVore JL, Ducatez S, Rollins LA. Increased adaptive variation despite reduced overall genetic diversity in a rapidly adapting invader. Front Genet 2019;10:1221. doi:10.3389/fgene.2019.01221.

[30] Brown GP, Kelehear C, Pizzatto L, Shine R. The impact of lungworm parasites on rates of dispersal of their anuran host, the invasive cane toad. Biol Invasions 2016;18:103-14. doi:10.1007/s10530-015-0993-1.

[31] Hudson CM, Brown GP, Shine R. Evolutionary shifts in anti-predator responses of invasive cane toads (Rhinella marina). Behav Ecol Sociobiol (Print) 2017;71:134. doi:10.1007/s00265017-2367-4.

[32] Kelehear C, Jones HI. Nematode larvae (order Spirurida) in gastric tissues of Australian anurans: a comparison between the introduced cane toad and sympatric native frogs. J Wildl Dis 2010;46:1126-40. doi:10.7589/0090-3558-46.4.1126.

[33] Baker MR. The free-living and parasitic development of Rhabdias spp. (Nematoda: Rhabdiasidae) in amphibians. Can J Zool 1979;57:161-78. doi:10.1139/z79-014.

[34] Bolyen E, Rideout JR, Dillon MR, Bokulich NA, Abnet C, Al-Ghalith GA, et al. QIIME 2: Reproducible, interactive, scalable, and extensible microbiome data science 2018. doi:10.7287/peerj.preprints.27295v1.

[35] Douglas GM, Maffei VJ, Zaneveld J, Yurgel SN, Brown JR, Taylor CM, et al. PICRUSt2: An improved and extensible approach for metagenome inference. BioRxiv 2019. doi:10.1101/672295.

[36] R Core Team. R: A language and environment for statistical computing. R Foundation for Statistical Computing, Vienna, Austria; 2020.

[37] Davidson GL, Cooke AC, Johnson CN, Quinn JL. The gut microbiome as a driver of individual variation in cognition and functional behaviour. Philos Trans R Soc Lond B, Biol Sci 2018;373. doi:10.1098/rstb.2017.0286.

[38] Rollins LA, Richardson MF, Shine R. A genetic perspective on rapid evolution in cane toads (Rhinella marina). Mol Ecol 2015;24:2264-76. doi:10.1111/mec.13184.

[39] Shine R. The impact of an invasive amphibian: the cane toad Rhinella marina. In: Heatwole H, Rowley J, editors. Status of Conservation and Decline of Amphibians: Australia, New Zealand, 
and Pacific Islands, Victoria, Australia: CSIRO Publishing; 2018, p. 107-24.

454

455

456

457

458

459

460

461

462

463

464

465

466

467

468

469

470

471

472

473

474

475

476

477

478

479

480

481

482

483

484

485

486

487

488

489

[40] Shine R, Brown GP, Phillips BL. An evolutionary process that assembles phenotypes through space rather than through time. Proc Natl Acad Sci USA 2011;108:5708-11. doi:10.1073/pnas.1018989108.

[41] Brown GP, Kelehear C, Shine R. The early toad gets the worm: cane toads at an invasion front benefit from higher prey availability. J Anim Ecol 2013;82:854-62. doi:10.1111/13652656.12048 .

[42] Kosmala GK, Brown GP, Shine R. Thin-skinned invaders: geographic variation in the structure of the skin among populations of cane toads (Rhinella marina). Biological Journal of the Linnean Society 2020;131:611-21. doi:10.1093/biolinnean/blaa128.

[43] Weitzman CL, Kaestli M, Gibb K, Brown GP, Shine R, Christian K. Disease exposure and antifungal bacteria on skin of invasive cane toads, australia. Emerging Infect Dis 2019;25:1770-1. doi:10.3201/eid2509.190386.

[44] Zhou J, Tesfamicael K, Zhou SJ, Rollins LA, Rodriguez Lopez CM. Genetic similarity enhances the strength of the relationship between gut bacteria and host DNA methylation. BioRxiv 2021. doi:10.1101/2021.07.10.451923.

[45] Zhang X-Y, Sukhchuluun G, Bo T-B, Chi Q-S, Yang J-J, Chen B, et al. Huddling remodels gut microbiota to reduce energy requirements in a small mammal species during cold exposure. Microbiome 2018;6:103. doi:10.1186/s40168-018-0473-9.

[46] Louis P, Flint HJ. Formation of propionate and butyrate by the human colonic microbiota. Environ Microbiol 2017;19:29-41. doi:10.1111/1462-2920.13589.

[47] Gamage HKAH, Tetu SG, Chong RWW, Ashton J, Packer NH, Paulsen IT. Cereal products derived from wheat, sorghum, rice and oats alter the infant gut microbiota in vitro. Sci Rep 2017;7:14312. doi:10.1038/s41598-017-14707-z.

[48] Thomas RH, Meeking MM, Mepham JR, Tichenoff L, Possmayer F, Liu S, et al. The enteric bacterial metabolite propionic acid alters brain and plasma phospholipid molecular species: further development of a rodent model of autism spectrum disorders. J Neuroinflammation 2012;9:153. doi:10.1186/1742-2094-9-153.

[49] Hugenholtz F, Davids M, Schwarz J, Müller M, Tomé D, Schaap P, et al. Metatranscriptome analysis of the microbial fermentation of dietary milk proteins in the murine gut. PLoS One 2018;13:e0194066. doi:10.1371/journal.pone.0194066.

[50] Kang D-W, Park JG, Ilhan ZE, Wallstrom G, Labaer J, Adams JB, et al. Reduced incidence of Prevotella and other fermenters in intestinal microflora of autistic children. PLoS One 2013;8:e68322. doi:10.1371/journal.pone.0068322.

[51] González-Bernal E, Brown GP, Shine R. Invasive cane toads: social facilitation depends upon an individual's personality. PLoS One 2014;9:e102880. doi:10.1371/journal.pone.0102880.

[52] Gelbard-Sagiv H, Magidov E, Sharon H, Hendler T, Nir Y. Noradrenaline modulates visual 
perception and late visually evoked activity. Curr Biol 2018;28:2239-2249.e6.

doi:10.1016/j.cub.2018.05.051.

[53] Houlden A, Goldrick M, Brough D, Vizi ES, Lénárt N, Martinecz B, et al. Brain injury induces specific changes in the caecal microbiota of mice via altered autonomic activity and mucoprotein production. Brain Behav Immun 2016;57:10-20. doi:10.1016/j.bbi.2016.04.003.

[54] Ning T, Gong X, Xie L, Ma B. Gut Microbiota Analysis in Rats with MethamphetamineInduced Conditioned Place Preference. Front Microbiol 2017;8:1620. doi:10.3389/fmicb.2017.01620.

[55] Choi JJ, Eum SY, Rampersaud E, Daunert S, Abreu MT, Toborek M. Exercise attenuates PCB-induced changes in the mouse gut microbiome. Environ Health Perspect 2013;121:72530. doi:10.1289/ehp.1306534.

[56] Golla A, Østby H, Kermen F. Chronic unpredictable stress induces anxiety-like behaviors in young zebrafish. Sci Rep 2020;10:10339. doi:10.1038/s41598-020-67182-4.

[57] Lozupone CA, Stombaugh JI, Gordon JI, Jansson JK, Knight R. Diversity, stability and resilience of the human gut microbiota. Nature 2012;489:220-30. doi:10.1038/nature11550.

[58] West TP. Degradation of pyrimidine ribonucleosides by Pseudomonas aeruginosa. Antonie Van Leeuwenhoek 1996;69:331-5. doi:10.1007/bf00399622.

507

508

509

[59] Garavaglia M, Rossi E, Landini P. The pyrimidine nucleotide biosynthetic pathway modulates production of biofilm determinants in Escherichia coli. PLoS One 2012;7:e31252. doi:10.1371/journal.pone.0031252.

[60] Bashiri G, Antoney J, Jirgis ENM, Shah MV, Ney B, Copp J, et al. A revised biosynthetic pathway for the cofactor F420 in prokaryotes. Nat Commun 2019;10:1558. doi:10.1038/s41467-019-09534-x.

[61] Sibon OCM, Strauss E. Coenzyme A: to make it or uptake it? Nat Rev Mol Cell Biol 2016;17:605-6. doi:10.1038/nrm.2016.110.

[62] Varki A, Gagneux P. Multifarious roles of sialic acids in immunity. Ann N Y Acad Sci 2012;1253:16-36. doi:10.1111/j.1749-6632.2012.06517.x.

[63] Liao H, Klaus C, Neumann H. Control of innate immunity by sialic acids in the nervous tissue. Int J Mol Sci 2020;21. doi:10.3390/ijms21155494.

[64] Sinnott-Armstrong N, Naqvi S, Rivas MA, Pritchard JK. GWAS of three molecular traits highlights core genes and pathways alongside a highly polygenic background. BioRxiv 2020. doi:10.1101/2020.04.20.051631.

[65] Brown GP, Shilton C, Phillips BL, Shine R. Invasion, stress, and spinal arthritis in cane toads. Proc Natl Acad Sci USA 2007;104:17698-700. doi:10.1073/pnas.0705057104. 
doi:10.1371/journal.pone.0023277.

527

528

529

530

531

532

533

534

535

536

537

538

539

540

541

542

543

544

545

546

547

548

549

550

551

552

553

554

555

556

557

558

559

560

561

[67] Poulin R. Parasite manipulation of host behavior: an updateand frequently asked questions. Advances In The Study Of Behavior, vol. 41, Elsevier; 2010, p. 151-86. doi:10.1016/S00653454(10)41005-0.

[68] Gegear RJ, Otterstatter MC, Thomson JD. Bumble-bee foragers infected by a gut parasite have an impaired ability to utilize floral information. Proc Biol Sci 2006;273:1073-8. doi:10.1098/rspb.2005.3423.

[69] Pizzatto L, Shine R. Lungworm infection modifies cardiac response to exercise in cane toads. J Zool 2012;287:150-5. doi:10.1111/j.1469-7998.2012.00898.x.

[70] Finnerty PB. The physiological and ecological impacts of lungworm infection on invasive cane toads. Undergraduate thesis. University of Sydney, 2017.

[71] Abada EA, Sung H, Dwivedi M, Park B-J, Lee S-K, Ahnn J. C. elegans behavior of preference choice on bacterial food. Mol Cells 2009;28:209-13. doi:10.1007/s10059-009-0124-x.

[72] Zheng D, Liwinski T, Elinav E. Interaction between microbiota and immunity in health and disease. Cell Res 2020;30:492-506. doi:10.1038/s41422-020-0332-7.

[73] Brown GP, Kelehear C, Shilton CM, Phillips BL, Shine R. Stress and immunity at the invasion front: a comparison across cane toad (Rhinella marina) populations. Biological Journal of the Linnean Society 2015;116:748-60. doi:10.1111/bij.12623.

[74] Hudson CM, Brown GP, Shine R. Evolutionary shifts in anti-predator responses of invasive cane toads (Rhinella marina). Behav Ecol Sociobiol (Print) 2017;71:134. doi:10.1007/s00265017-2367-4.

[75] Zhang C, Zhang M, Wang S, Han R, Cao Y, Hua W, et al. Interactions between gut microbiota, host genetics and diet relevant to development of metabolic syndromes in mice. ISME J 2010;4:232-41. doi:10.1038/ismej.2009.112.

[76] Fan P, Bian B, Teng L, Nelson CD, Driver J, Elzo MA, et al. Host genetic effects upon the early gut microbiota in a bovine model with graduated spectrum of genetic variation. ISME J 2020;14:302-17. doi:10.1038/s41396-019-0529-2.

[77] Arnaud-Haond S, Aires T, Candeias R, Teixeira SJL, Duarte CM, Valero M, et al. Entangled fates of holobiont genomes during invasion: nested bacterial and host diversities in Caulerpa taxifolia. Mol Ecol 2017;26:2379-91. doi:10.1111/mec.14030.

[Preprint] Zhou J, Nelson TM, Rodriguez Lopez C, Zhou SJ, Ward-Fear G, Stuart KC, et al. The gut bacteria of an invasive amphibian respond to the dual challenges of range-expansion and parasite attack. BioRxiv 2020. doi:10.1101/2020.11.16.385690. 


\section{Tables and Figures}

563 Table 1a-d. The association between a) single host factors and microbial community, b) single host

564 factors and predicted microbial function, c) single behavioural trait and microbial community and d)

565 single behavioural trait and predicted microbial function. Significant p-values denoted by an asterisk.

MDS1

MDS2

r2

$\operatorname{Pr}(>\mathrm{r})$

a. Host factor/microbial community

SUL

0.170

0.985

0.071

0.119

BodyWeight

$-0.009$

1.000

0.051

0.231

Lungworms

0.254

$-0.967$

0.020

0.585

Occurrence of lungworms

0.453

$-0.892$

0.128

$0.023^{*}$

\section{b. Host factor/microbial function}

SUL

0.680

0.733

0.021

0.556

BodyWeight

0.610

0.793

0.041

0.311

Lungworms

$-0.791$

0.612

0.007

0.839

Occurrence of lungworms

$-0.827$

$-0.562$

0.059

0.187

c. Behavioural trait/microbial community

Struggle score

Struggle likelihood

Righting effort

Righting effort likelihood

Righting time
$-0.814$

$-0.880$

$-0.124$

0.499

0.933
0.580

0.044

0.268

$-0.474$

0.021

0.555

$0.992 \quad 0.075$

0.121

$0.867 \quad 0.0255$

0.474

$\begin{array}{ll}0.360 & 0.0615\end{array}$

0.174 


$\begin{array}{lcccc}\text { Struggle score } & 0.376 & 0.927 & 0.051 & 0.221 \\ \text { Struggle likelihood } & 0.183 & 0.983 & 0.017 & 0.606 \\ \text { Righting effort } & 0.571 & 0.821 & 0.070 & 0.141 \\ \text { Righting effort likelihood } & 0.399 & 0.917 & 0.035 & 0.362 \\ \text { Righting time } & -0.956 & -0.294 & 0.004 & 0.894\end{array}$

569 Table 2. Association between gut microbiota variation and lungworm occurrence and intensity, based 570 on Bray Curtis dissimilarity values for microbial community assemblages.

\begin{tabular}{lccccc}
\hline & Df & SumOfSqs & R2 & F & Pr(>F) \\
\hline Location & 1 & 1.314 & 0.091 & 6.026 & $<0.001^{* * *}$ \\
Lungworm_occurrence & 1 & 0.482 & 0.033 & 2.213 & $0.005^{* *}$ \\
Lungworms_intensity & 1 & 0.150 & 0.010 & 0.688 & 0.861 \\
Location:Lungworm_occurrence & 1 & 0.331 & 0.023 & 1.520 & 0.075 \\
Location:Lungworm_intensity & 1 & 0.357 & 0.025 & 1.638 & $0.043 *$ \\
Residual & & & & & \\
Total & 54 & 11.774 & 0.817 & & \\
\hline
\end{tabular}

Significance codes: 0 '***’ $\leq 0.001^{\text {'*** }} \leq 0.01^{\text {'* } *} \leq 0.05$. 

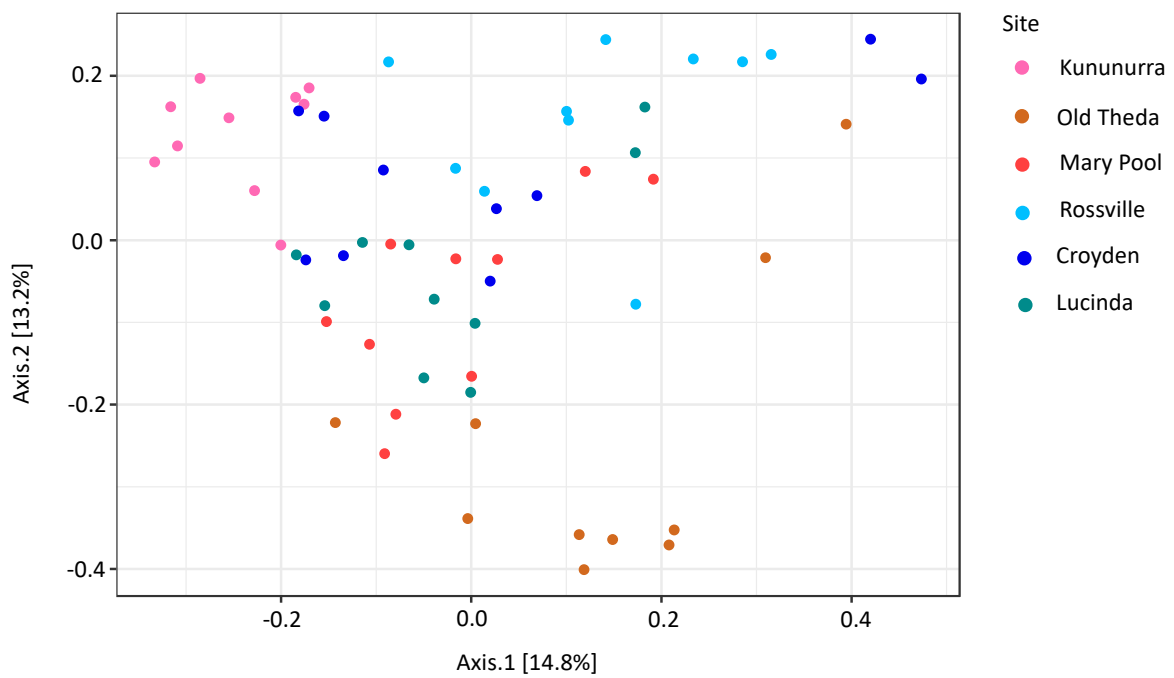

Microbial predicted functions - Bray Curtis

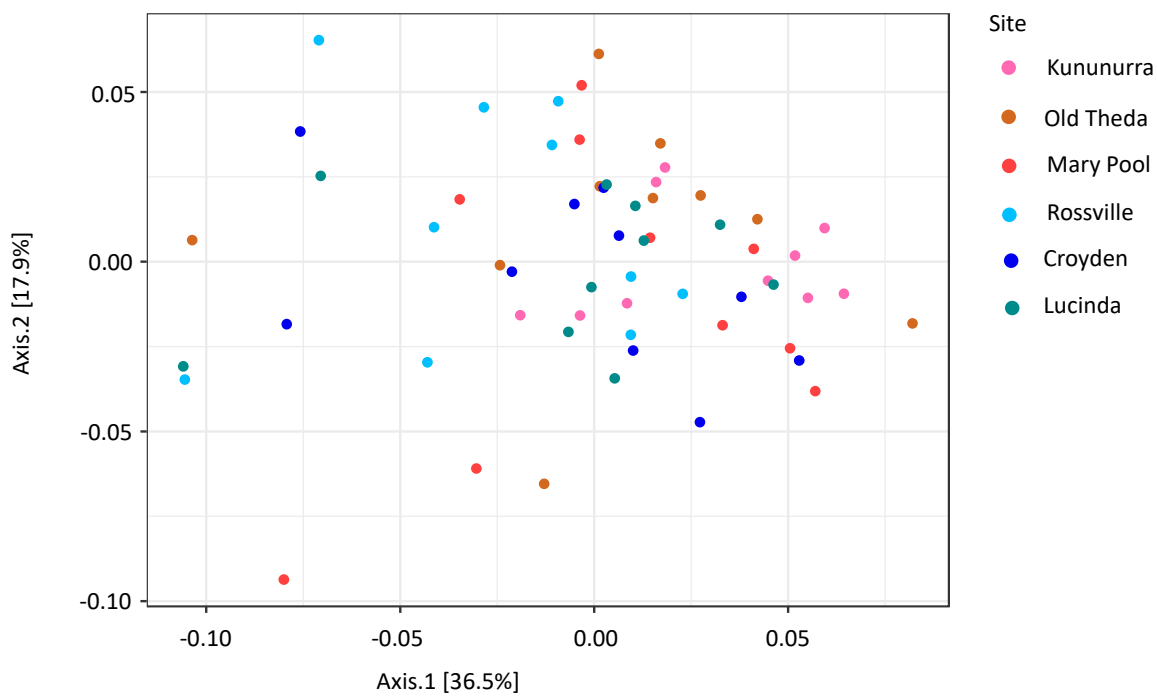

Figure 1. Beta diversity by location. Principle coordinate analysis plot of Bray Curtis distance of microbial community (A) and Bray Curtis distance of predicted functional groups (B) from 60 cane toad individuals of the invasion-front (Kununurra, Old Theda, and Mary Pool) and the range-core

581 (Rossville, Croydon, and Lucinda). 
Phylum

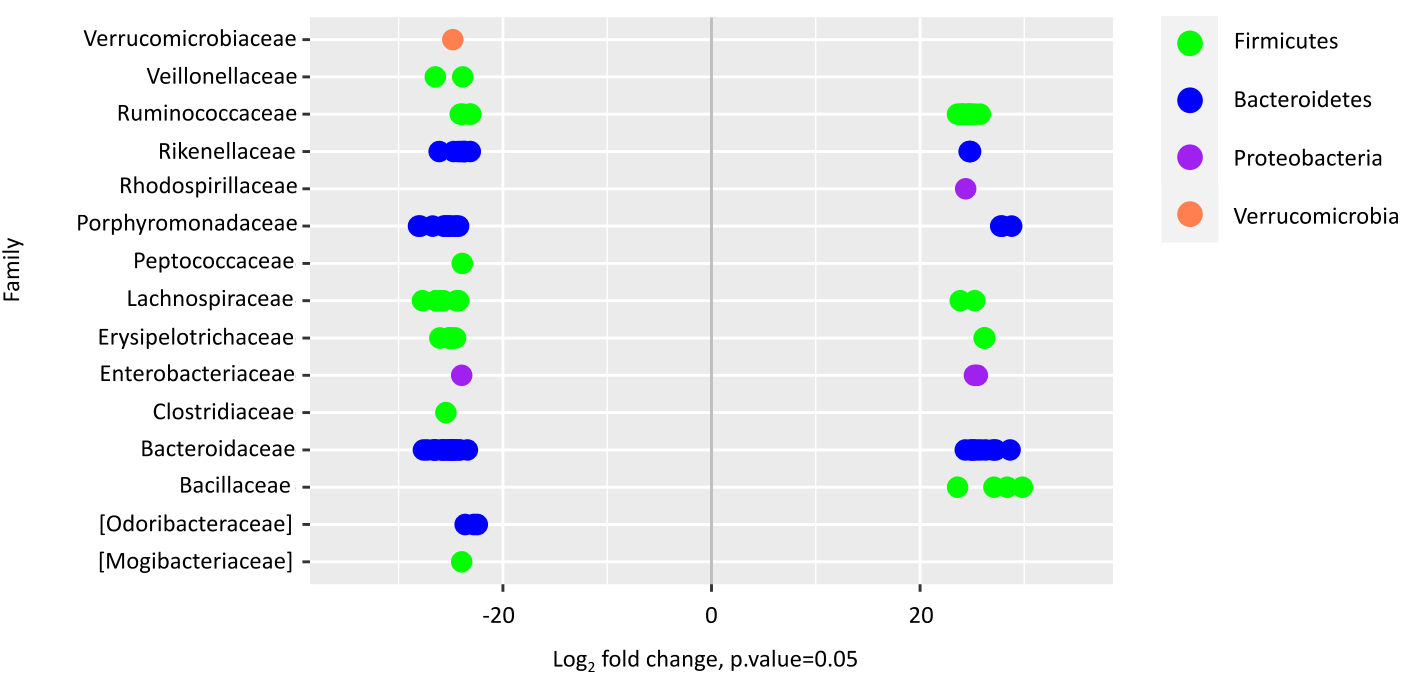

B

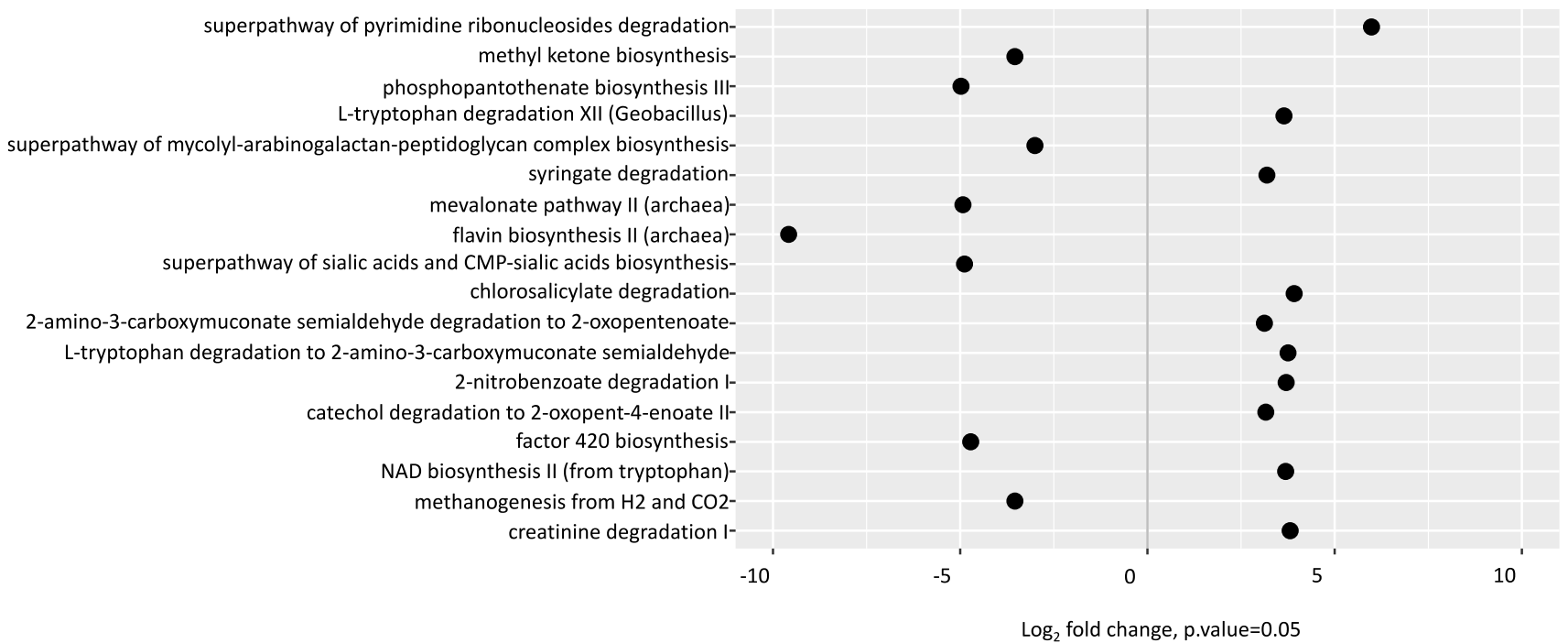
(QLD) and invasion-front (WA) toads' colon. Significant differences were identified between locations via differential abundance testing based on a negative binomial distribution. The dots represent the average log-2 fold change ( $\mathrm{x}$ axis) abundance and positive $\log _{2}$ fold changes signify increased abundance in range-core, and negative $\log _{2}$ fold changes display increased abundance in invasion-front. Bacterial taxa (A) were classified to the taxonomic level of family (y axis) and coloured by taxonomic level of phylum. Family name in bracket is proposed taxonomy by Greengenes. Only ASVs that could be matched to a known bacterial family and with a $\log 2$ FoldChange value higher than 20 or lower than -20 are presented. Predicted functions (B) with a $\log 2$ FoldChange value higher than 3 or lower than -3 are presented. 


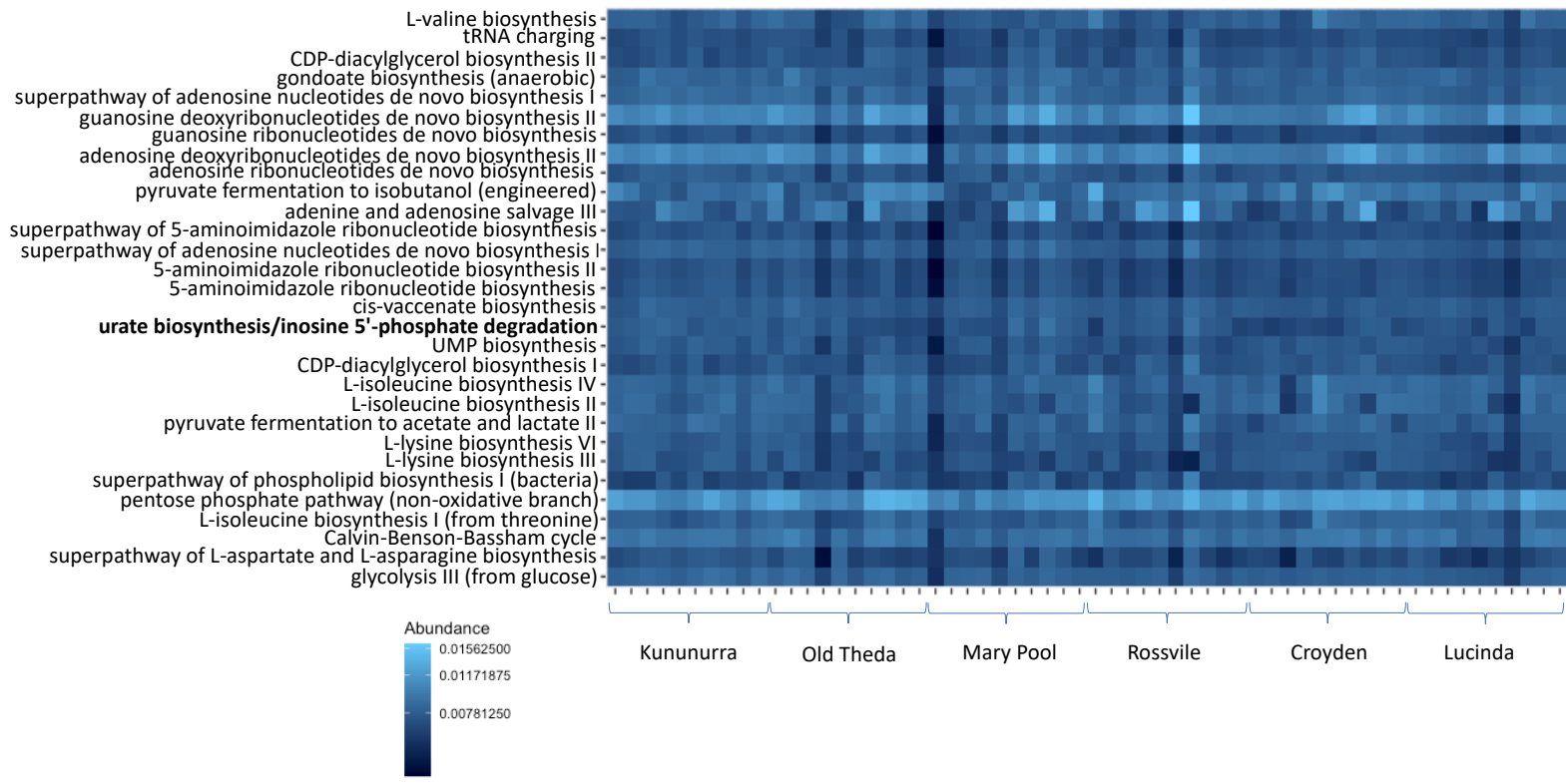

601 Figure 3. Heatmap for top 30 functional group abundance.

602 Heatmap indicates the top 30 functional groups in the intestinal samples from range-core and 603 invasion-front toads. Abundance indicates the raw count of functional groups inferred from 604 taxonomic 16S sequences using PICRUSt where light blue is high abundance and dark blue is lower 605 abundance. Functional pathways that differ significantly between range-core and invasion-front toads 606 are highlighted in bold. Range-core includes Rossville, Croyden, and Lucinda; invasion-front 607 includes Kununurra, Old Theda, and Mary Pool.

608

609

610

611

612

613 


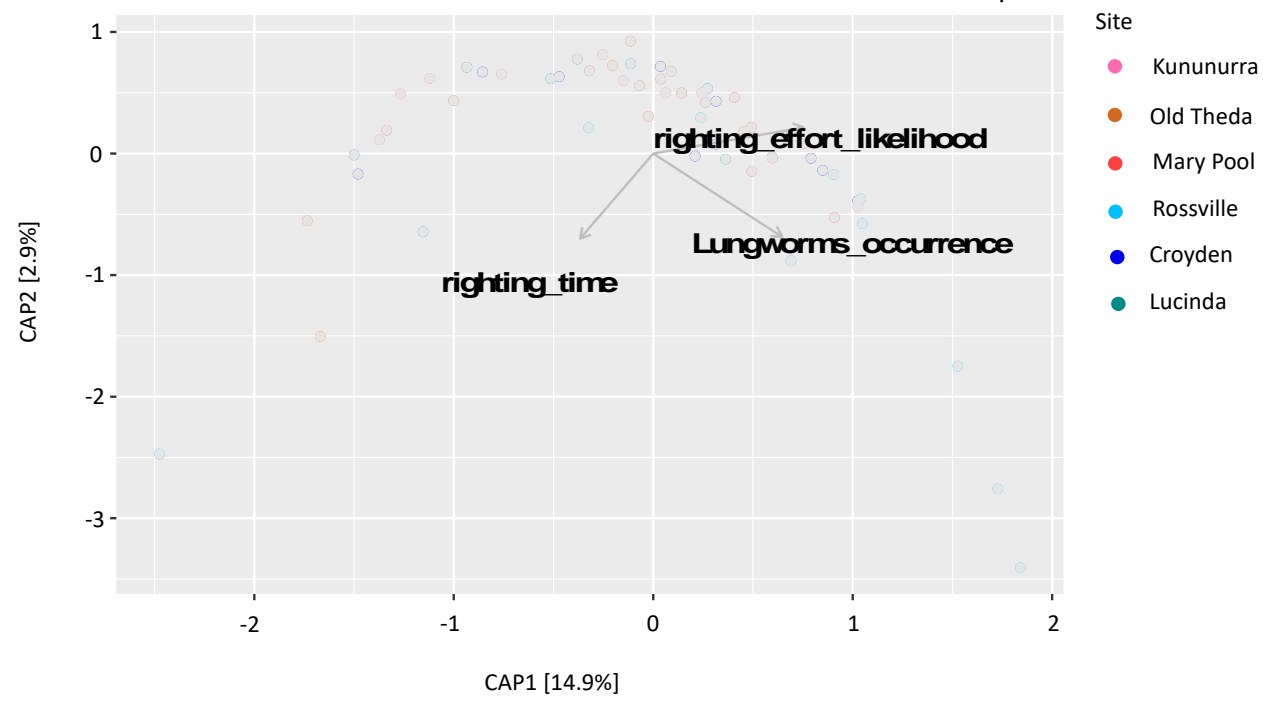

616 Figure 4. Main variables that affect predicted function differentiation among individuals. CAP

617 (capscale) plot displays the combination of variables that explained the greatest variation in the

618 predicted functions through model selection, using 60 cane toad individuals from the invasion-front

619 (Kununurra, Old Theda, and Mary Pool) and the range-core (Rossville, Croydon, and Lucinda). The

620 final model explained $17.8 \%$ of variation in the microbial predicted functions, which includes

621 righting effort likelihood ( $\mathrm{AIC}=53.613$ ), occurrence of lung worms $(\mathrm{AIC}=54.297)$ and righting

622 time $(\mathrm{AIC}=56.912)$ explained the greatest variation. 
A Microbial community - Bray Curtis

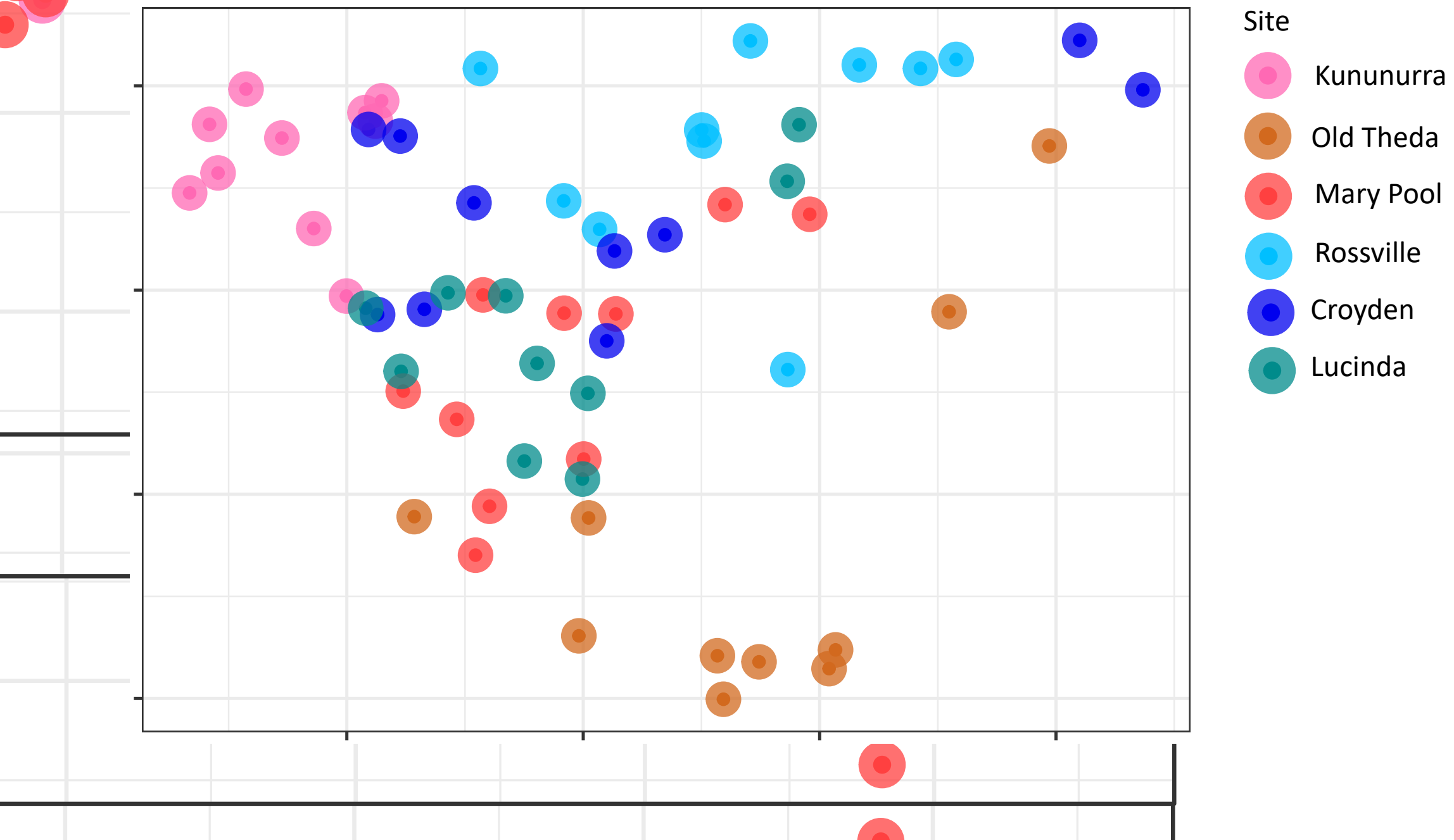




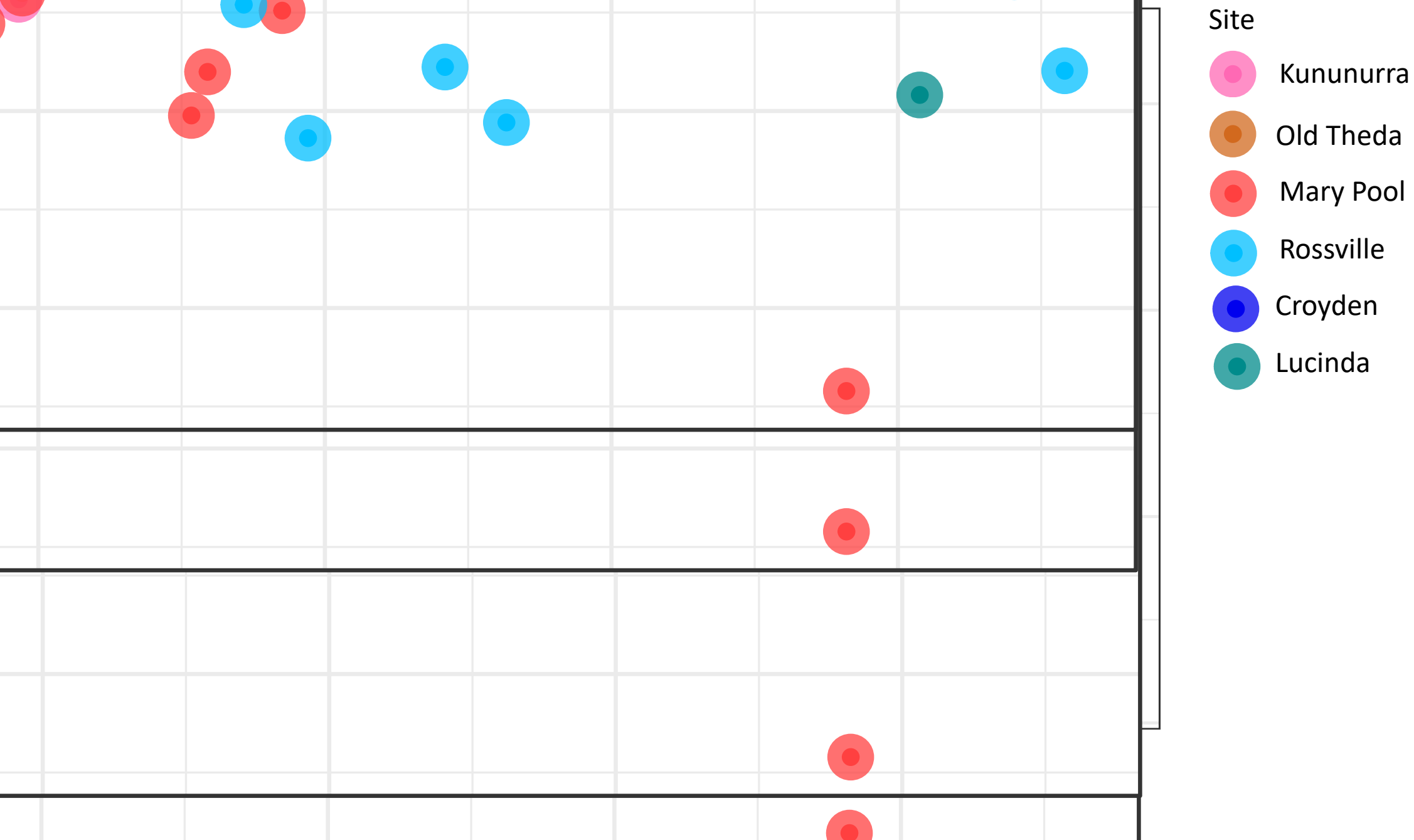




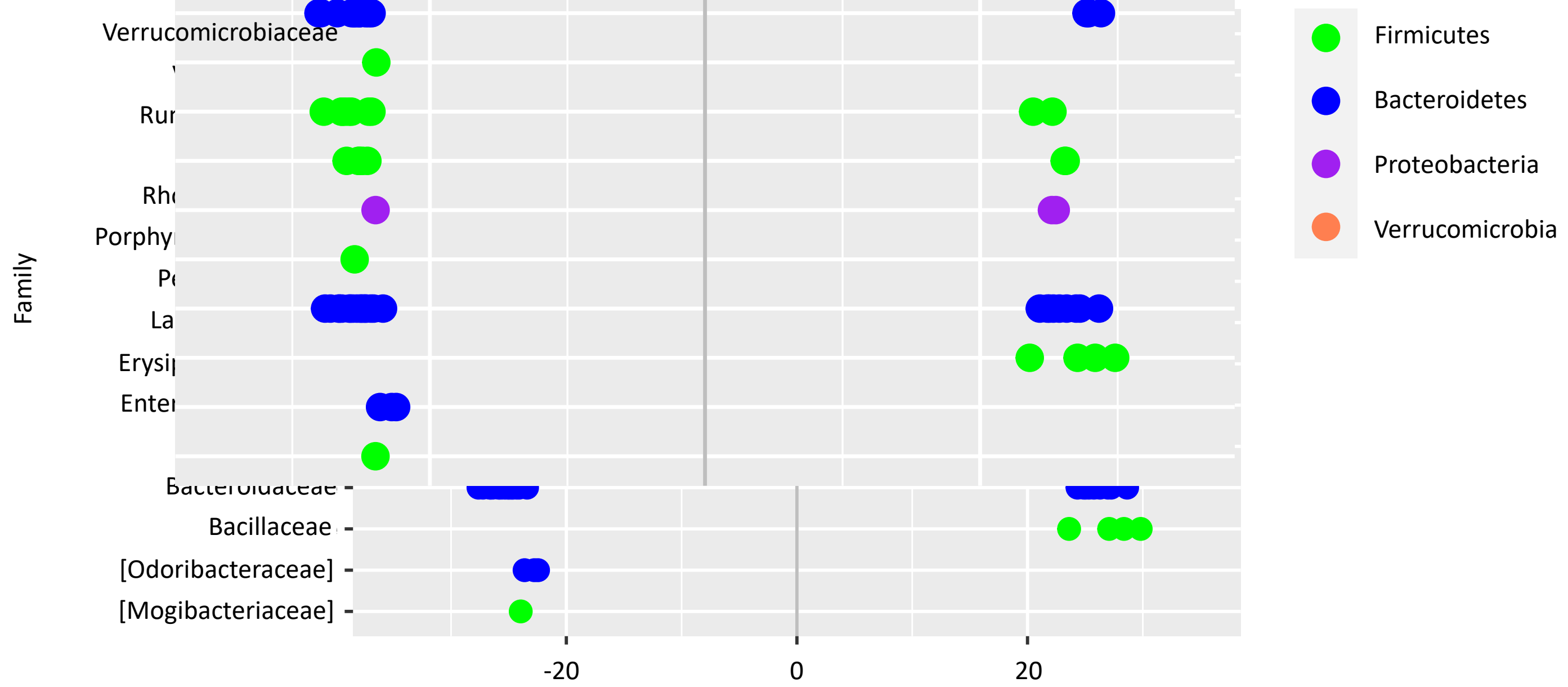

$\log _{2}$ fold change, p.value $=0.05$ 
superpathway of pyrimidine ribonucleosides degradationmethyl ketone biosynthesisphosphopantothenate biosynthesis IIIL-tryptophan degradation XII (Geobacillus)superpathway of mycolyl-arabinogalactan-peptidoglycan complex biosynthesissyringate degradationmevalonate pathway II (archaea)flavin biosynthesis II (archaea)superpathway of sialic acids and CMP-sialic acids biosynthesischlorosalicylate degradation2-amino-3-carboxymuconate semialdehyde degradation to 2-oxopentenoateL-tryptophan degradation to 2-amino-3-carboxymuconate semialdehyde2-nitrobenzoate degradation Icatechol degradation to 2-oxopent-4-enoate IIfactor 420 biosynthesisNAD biosynthesis II (from tryptophan)methanogenesis from $\mathrm{H} 2$ and $\mathrm{CO}_{2}-$ creatinine degradation I-

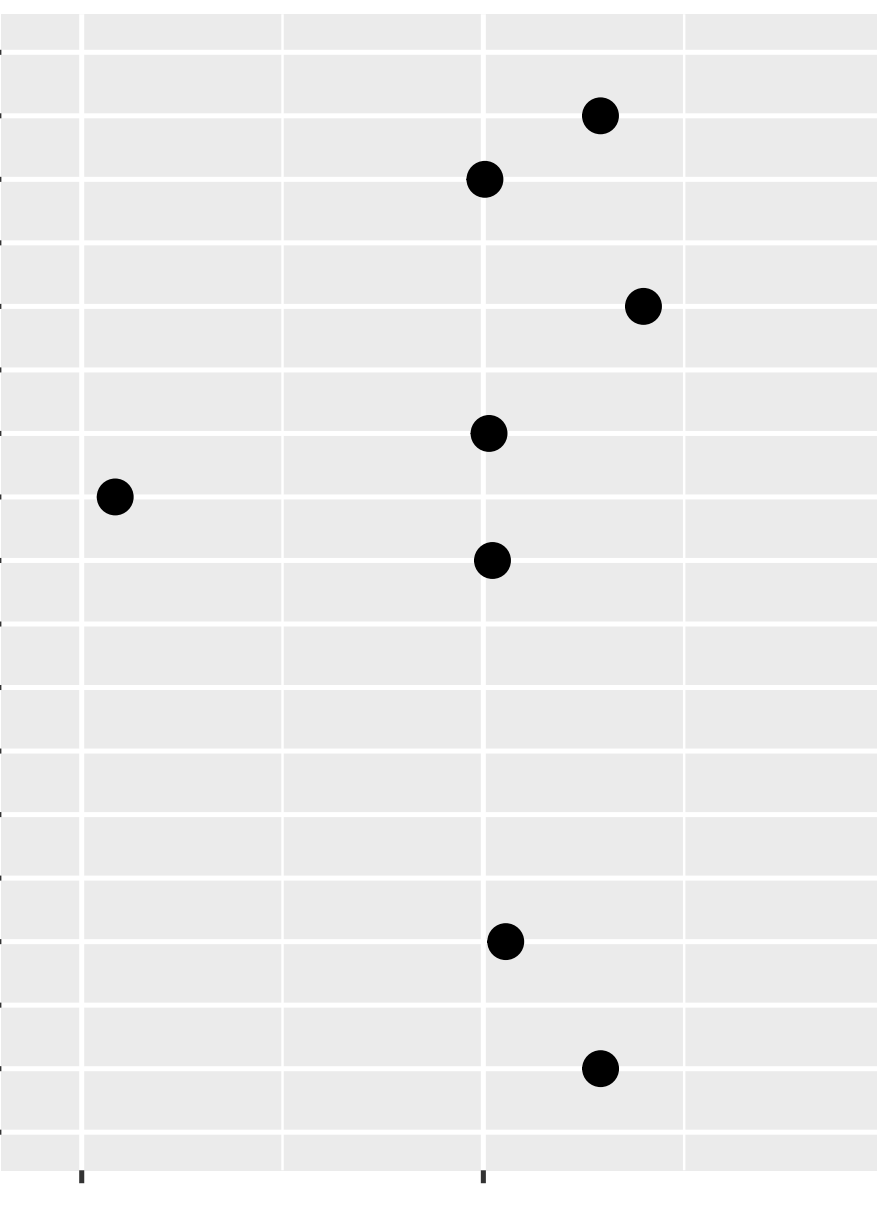

$-10$

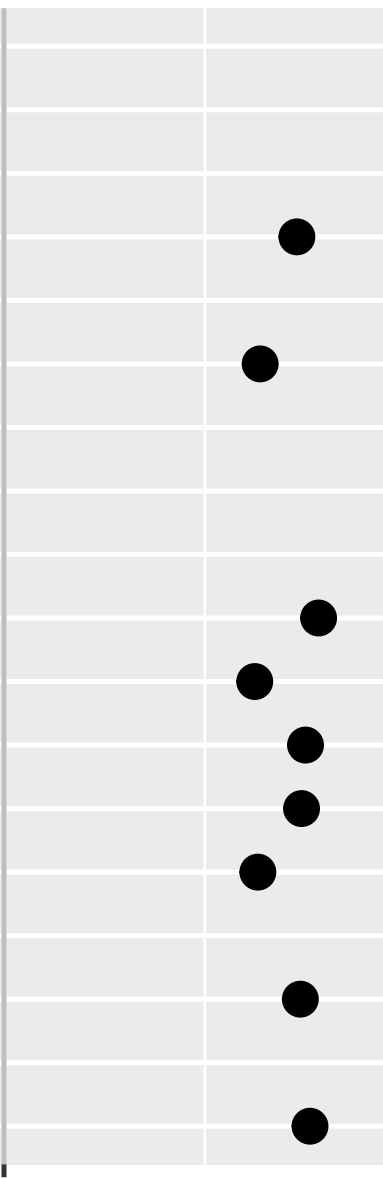

5

$\log _{2}$ fold change, p.value $=0.05$ 

L-valine biosynthesis
tRNA charging

CDP-diacylglycerol biosynthesis II gondoate biosynthesis (anaerobic) superpathway of adenosine nucleotides de novo biosynthesis I guanosine deoxyribonucleotides de novo biosynthesis II guanosine ribonucleotides de novo biosynthesis adenosine deoxyribonucleotides de novo biosynthesis II pyruvate fermentation to isobutanol (engineered) adenine and adenosine salvage III superpathway of 5-aminoimidazole ribonucleotide biosynthesis superpathway of adenosine nucleotides de novo biosynthesis I

5-aminoimidazole ribonucleotide biosynthesis II 5-aminoimidazole ribonucleotide biosynthesis cis-vaccenate biosynthesis
urate biosynthesis/inosine 5 '-phosphate degradation UMP biosynthesis CDP-diacylglycerol biosynthesis I L-isoleucine biosynthesis IV L-isoleucine biosynthesis II pyruvate fermentation to acetate and lactate II L-lysine biosynthesis VI
L-lysine biosynthesis III superpathway of phospholipid biosynthesis I (bacteria) pentose phosphate pathway (non-oxidative branch

L-isoleucine biosynthesis I (from threonine) Calvin-Benson-Bassham cycle superpathway of L-aspartate and L-asparagine biosynthesis glycolysis III (from glucose)

Abundance

0.01562500

0.01171875

0.00781250

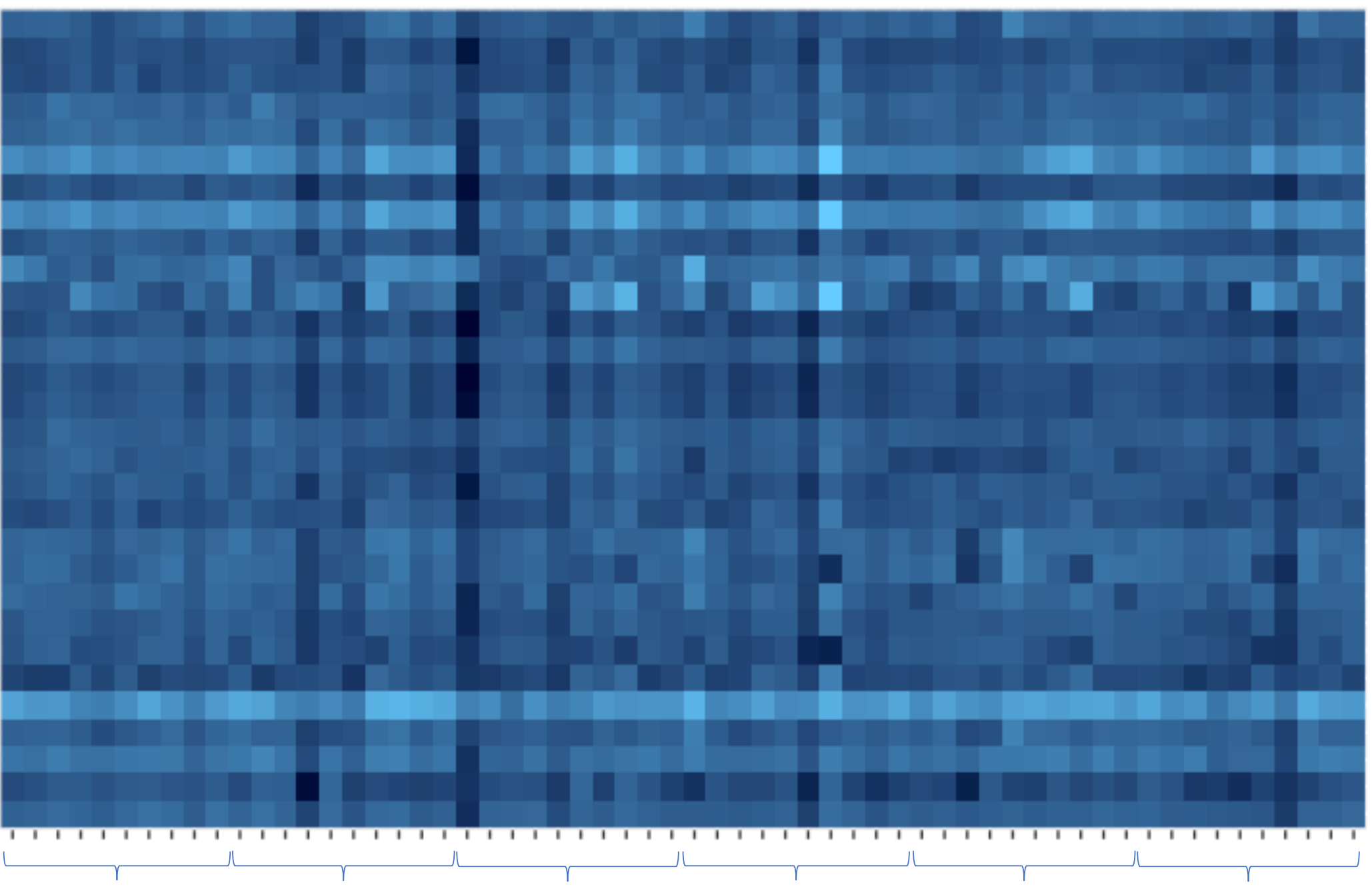

Kununurra Old Theda Mary Pool Rossvile Croyden Lucinda 


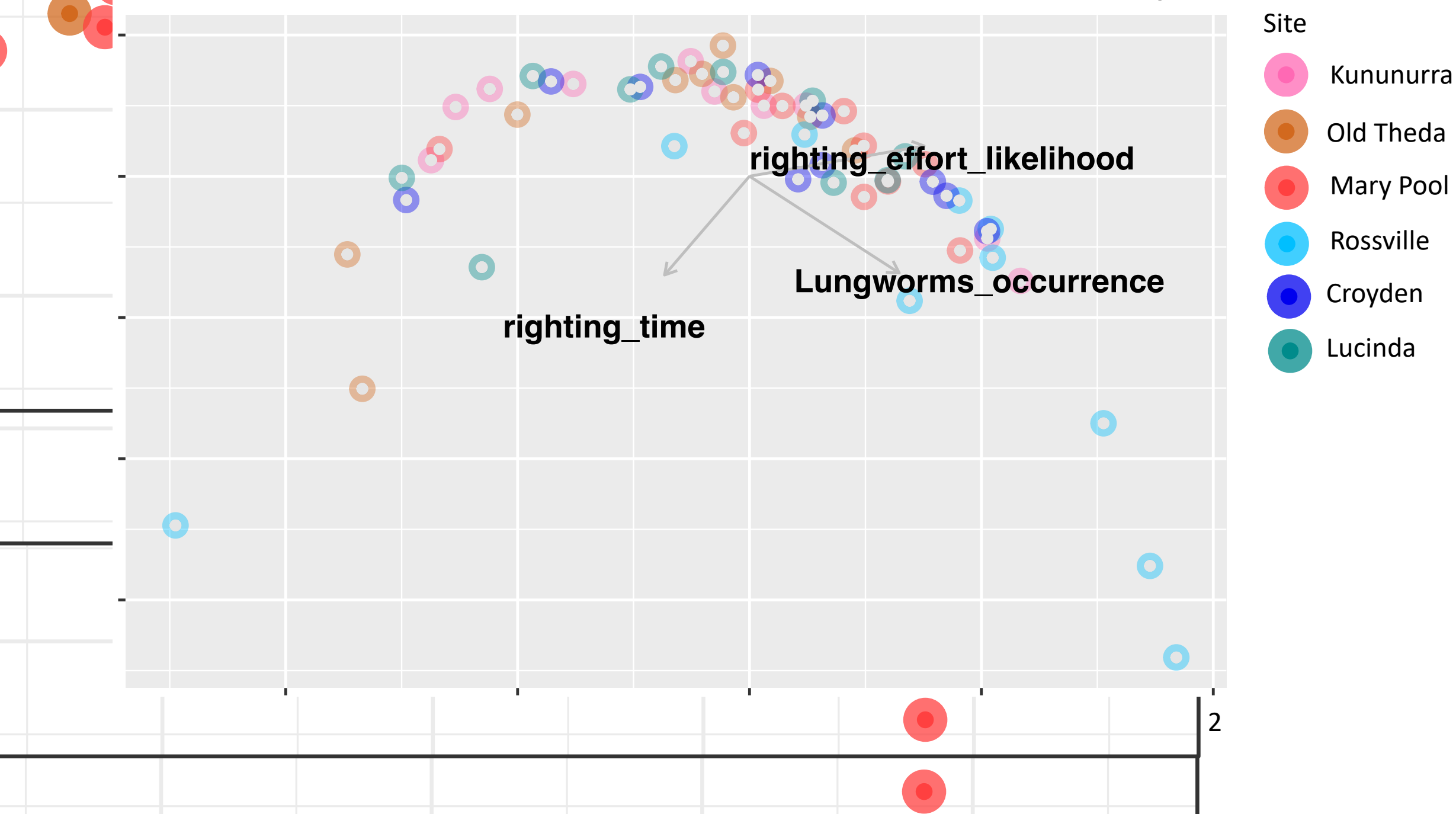

